\title{
Long-term synaptic plasticity in hippocampal neurogliaform interneurons
}

Marion S. Mercier ${ }^{\mathrm{a}}$, Vincent Magloire ${ }^{\mathrm{a}}$, Jonathan Cornford ${ }^{\mathrm{a}}$, Dimitri M. Kullmann ${ }^{\mathrm{a} *}$

\begin{abstract}
Affiliations:
${ }^{a} U C L$ Queen Square Institute of Neurology, Department of Clinical and Experimental Epilepsy, University College London, WC1N 3BG

*Correspondence to: d.kullmann@ucl.ac.uk
\end{abstract}

Short title: LTP in hippocampal neurogliaform interneurons 


\begin{abstract}
Hippocampal interneurons located within stratum lacunosum-moleculare (SLM), which include neurogliaform (NGF) cells, mediate powerful feed-forward inhibition that can modulate spiking and plasticity in CA1 pyramidal cells. Despite evidence of long-term plasticity at excitatory inputs onto almost all other hippocampal interneuron subtypes, including stratum radiatum feed-forward interneurons, it is not known whether long-term potentiation (LTP) occurs in CA1 SLM interneurons. Here, we show that these interneurons exhibit Hebbian NMDA receptor-dependent LTP, and that $\mathrm{Ca}^{2+}$ influx through voltage-gated $\mathrm{Ca}^{2+}$ channels can also be sufficient for induction of plasticity. Furthermore, using an optogenetic dissection strategy, we find that selective stimulation of excitatory fibers from entorhinal cortex can induce LTP in SLM interneurons, whilst stimulation of thalamic afferents from the nucleus reuniens, also known to project to SLM, does not. Finally, we show that a mouse line selective for cortical NGF cells, where Cre recombinase is under the control of the neuron-derived neurotrophic factor (NDNF) promoter, can also be used to target these interneurons within the hippocampus, and that hippocampal NGF cells exhibit LTP. Recruitment of NGF cells can thus be persistently enhanced in an activity-dependent manner, implying that their role in gating dendritic signaling in pyramidal neurons is modifiable.
\end{abstract}

Keywords: neurogliaform, interneuron, plasticity, hippocampus, NDNF 


\section{Significance statement}

Long-term potentiation (LTP) of synaptic transmission within the hippocampus is involved in memory formation and spatial navigation. While LTP has been extensively studied in excitatory principal cells, less is known about plasticity mechanisms in inhibitory interneurons, which represent a diverse population of cells. Here we characterize LTP in interneurons that mediate powerful feed-forward inhibition of pyramidal neuron distal dendrites, and show that this plasticity can be induced by afferents originating in the entorhinal cortex. Importantly, we identify at least a subset of these LTP-expressing interneurons as neurogliaform cells. The results shed light on this relatively understudied sub-type of hippocampal interneurons and show that their recruitment by extrinsic afferents can be modified in a use-dependent manner. 


\section{Introduction}

Long-term potentiation (LTP) of excitatory neurotransmission has been extensively studied in the hippocampus, where it is thought to play a pivotal role in memory encoding. While the overwhelming majority of studies have focused on plasticity in principal cells, excitatory inputs onto a variety of inhibitory interneuron subtypes also undergo activitydependent changes (1-4). Thus, within hippocampal area CA1, LTP has been described at glutamatergic inputs onto interneurons located in strata oriens (5-8), pyramidale (9-11), and radiatum $(12,13)$, and notably may serve a number of important functions. LTP at Schaffer collateral (SC) synapses onto radiatum feed-forward interneurons, for instance, leads to an increase in disynaptic feed-forward inhibition of pyramidal neurons. This phenomenon has been proposed to preserve the temporal fidelity of synaptic integration in pyramidal cells that would otherwise be compromised by LTP occurring exclusively at monosynaptic SC inputs (12). Surprisingly, very few studies have investigated plasticity in interneurons located in stratum lacunosum moleculare (SLM), despite the powerful feed-forward inhibition known to be mediated by these cells. Indeed, stimulation of excitatory projections within SLM recruits such strong feed-forward inhibition that responses in upstream CA1 pyramidal cells are dominated by a large and long-lasting inhibitory current, mediated by both $\mathrm{GABA}_{\mathrm{A}}$ and $\mathrm{GABA}_{\mathrm{B}}$ receptor activation (14-16).

Excitatory fibers within the SLM, which originate primarily in entorhinal cortex (EC) layer III, constitute the temporoammonic (TA) pathway or the direct cortical input to the hippocampus, and synapse on the distal dendrites of CA1 pyramidal cells (17-19), as well as onto interneurons located in SLM (20). This direct cortical pathway interacts nonlinearly with SC inputs to CA1 pyramidal cells to facilitate synaptic plasticity (21-25), dendritic plateau potentials $(22,26)$, and the formation of new place fields (26). Importantly, however, when TA stimulation is timed for optimal recruitment of SLM feed-forward inhibition, it has also been shown to negatively modulate pyramidal cell output. Thus, bursts of TA activity can block both CA1 pyramidal cell spiking $(15,27)$ and induction of $\operatorname{LTP}(27,28)$ in response to SC stimulation, effects that were found to be $\mathrm{GABA}_{\mathrm{B}}$ and $\mathrm{GABA}_{\mathrm{A}}$ receptor-dependent, respectively. In addition, TA pathway inhibition is disrupted in pathological conditions such as temporal lobe epilepsy (29) and tauopathy (30), highlighting its possible significance in disease.

A heterogenous population of interneurons has been reported to reside within SLM, or on the border between SLM and stratum radiatum (31-33). Of these, perforant path-associated 
and neurogliaform (NGF) cells are the two cell-types most likely to underlie the prominent feed-forward inhibition seen in this pathway. Indeed, their dendrites are largely confined to SLM and, in the case of perforant path-associated cells, also stratum radiatum, suggesting that they receive very little, if any, feed-back excitation from local CA1 pyramidal cells $(32,34)$. NGF cells in particular are abundant, constituting $\sim 10 \%$ of the total inhibitory cell population within hippocampal area CA1 (35), and are known to signal via volume transmission (36), evoking exceptionally long-lasting inhibitory responses in postsynaptic cells, mediated by both $\mathrm{GABA}_{A}$ and $\mathrm{GABA}_{B}$ receptors. Thus, stimulation of NGF cells evokes responses that closely mimic those seen upon electrical stimulation of SLM, suggesting a dominant role for this celltype in SLM feed-forward inhibition.

It is not known whether NGF cells, or indeed any of the interneurons located within CA1 SLM, express LTP, as has now been described in the vast majority of other inhibitory cell-types found within the hippocampus (2). Furthermore, in addition to excitation from the $\mathrm{EC}$, this stratum of the hippocampus is also known to receive excitatory inputs from the nucleus reuniens (NRe) of the thalamus (37). These thalamic afferents effectively recruit hippocampal inhibition (38, 39), including NGF cells (40), and could also be susceptible to activitydependent changes. Using a combination of electrical and optogenetic stimulation, as well as a recently developed mouse line designed to selectively target cortical NGF cells (41), we show that LTP is induced by excitatory inputs from the EC, but not the thalamus, onto SLM interneurons, and that NGF cells constitute one of the inhibitory cell-types expressing this form of long-term plasticity. 


\section{Results}

\section{LTP in SLM interneurons.}

We recorded from interneurons in CA1 SLM with small round somata, consistent with NGF cell morphology (34), and stimulated fibers in the same layer in order to assess whether excitatory inputs onto these cells exhibit long-term plasticity (Fig. 1A). We restricted attention to the initial slope of excitatory postsynaptic potentials (EPSPs) and initially employed a lowfrequency stimulation (LFS) protocol paired with postsynaptic depolarization (LFS-P; Fig. 1A) in order to look for LTP at monosynaptic inputs (42). LFS-P led to an increase in EPSP slope to $129 \pm 9 \%$ of baseline, lasting for at least 30 minutes (Fig. $1 B ; \mathrm{n}=19 ; P<0.01$, paired $t$-test). LTP of a similar magnitude (134 $\pm 10 \%)$ could also be induced by high-frequency stimulation (HFS) of the SLM (Fig. S1A and $B ; \mathrm{n}=6 ; P=0.05$, paired $t$-test). Dual pathway experiments revealed a $20 \%$ larger increase of EPSP slope in the test relative to the control pathway following LFS-P (Fig. $1 C$; test: $135 \pm 15 \%$, control: $115 \pm 10 \%, \mathrm{n}=7 ; P=0.07$, paired $t$-test). This difference did not reach statistical significance, implying that LTP may not be fully restricted to stimulated synapses, as might be expected in cells with aspiny dendrites $(34,43$, 44). Consistent with classical Hebbian LTP mechanisms, LFS-P-induced LTP in SLM interneurons was NMDA receptor-dependent as its induction was fully blocked by application of APV $(100 \mu \mathrm{M}$; Fig. $1 D$; interleaved LFS-P: $142 \pm 7 \%, \mathrm{n}=5$; APV: $95 \pm 8 \%, \mathrm{n}=5 ; P<$ 0.01, unpaired $t$-test). Importantly, control experiments confirmed that responses were stable over time in the absence of experimental manipulation (Fig. S1C; responses $99 \pm 11 \%$ of baseline after $30 \mathrm{~min}$ recording, $\mathrm{n}=4$ ).

SLM interneuron dendrites have been shown to support back-propagating action potentials (APs) (45), and we hypothesized that appropriately timed conjunction of pre- and postsynaptic spiking underlies plasticity in these cells. To test this prediction, we applied a spike timing-dependent plasticity (STDP) protocol consisting of 30 presynaptic stimuli, each followed by a single postsynaptic spike (Fig. $2 A$ ). This induced a significant increase in EPSP slope to $140 \pm 14 \%$ of baseline (Fig. $2 B ; \mathrm{n}=8 ; P<0.05$, paired $t$-test). Interestingly, LTP induced by the STDP protocol was not pathway specific, as a very similar increase in EPSP size was also observed in a control pathway that was not stimulated during the pairing (Fig $2 B$; $137 \pm 12 \% ; \mathrm{n}=8$ ). Paired-pulse stimulation applied within and across pathways (see $S I$ Materials and Methods) confirmed that the two pathways were independent of each other (Fig. S2). These results imply that a postsynaptic LTP-induction cascade can spread from stimulated 
A

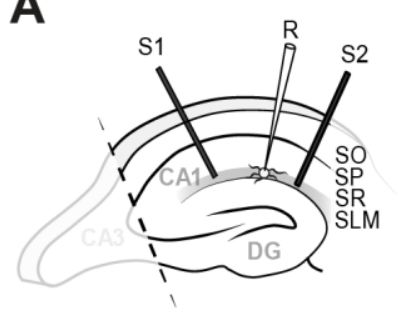

LTP induction protocol: LFS-P

200 pulses @ $2 \mathrm{~Hz}$

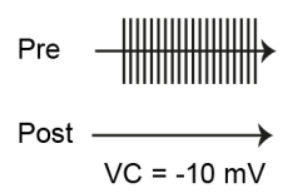

B
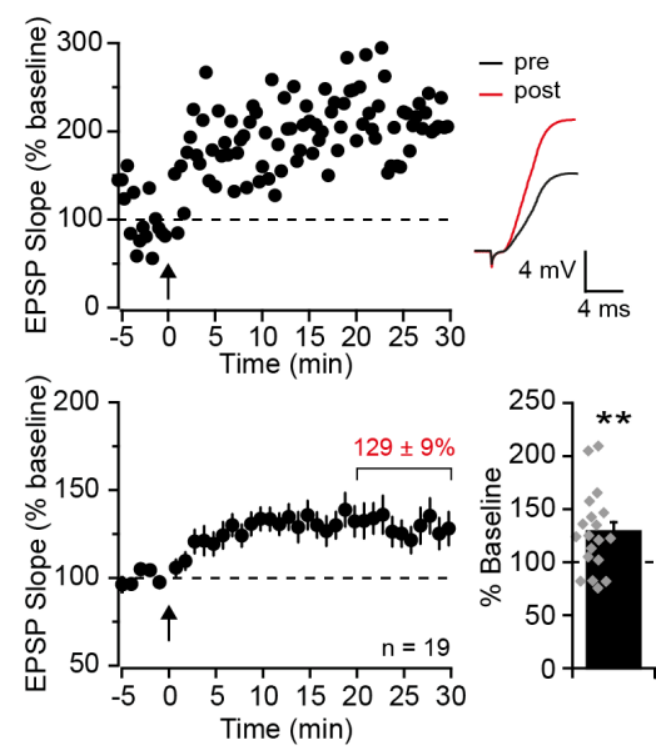

C
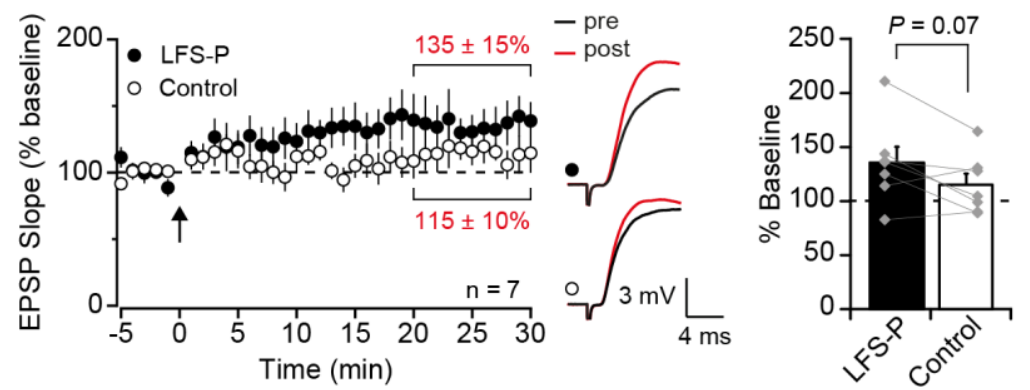

D
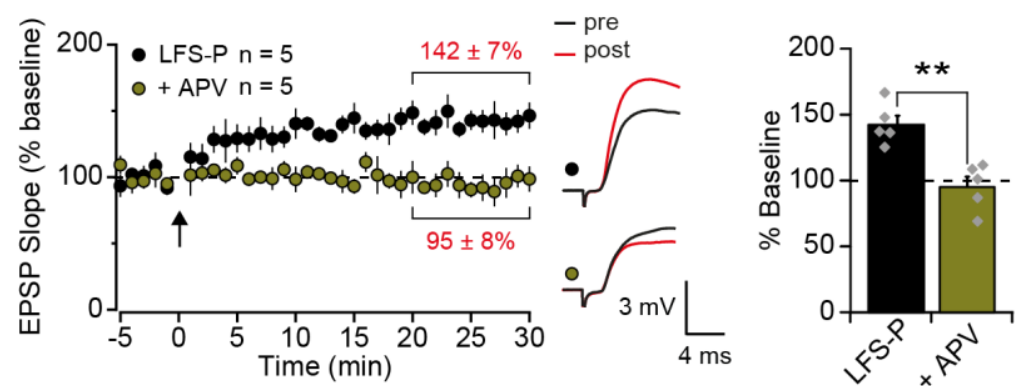

Fig. 1. NMDA receptor-dependent LTP in SLM interneurons. (A) Top: experimental setup showing placement of one recording (R) and two stimulating (S1, S2) electrodes in SLM of a hippocampal slice with CA3 removed. Bottom: schematic of the low-frequency stimulation-pairing (LFS-P) LTP induction protocol. $\mathrm{VC}=$ voltage clamp. $(B)$ Representative experiment and traces (top) and pooled dataset (bottom) showing LTP in SLM interneurons, quantified on bottom right. Arrows indicate LTP induction protocol. $(C)$ LFS-P-induced LTP was largely pathway-specific, quantified on right. $(D)$ Application of APV $(100 \mu \mathrm{M})$ blocked the induction of LTP by LFS-P, quantified on right. $* *=P<$ 0.01. Error bars show standard error of the mean (SEM).

to non-stimulated synapses, and/or that $\mathrm{Ca}^{2+}$ influx through voltage-gated $\mathrm{Ca}^{2+}$ channels (VGCCs) triggered by back-propagating APs is sufficient to induce plasticity throughout the dendritic tree. Several observations support the latter hypothesis: firstly, eliciting 30 
postsynaptic spikes alone, in the absence of presynaptic stimulation, was sufficient to induce an initial, although not sustained, increase in EPSP slope to $126 \pm 8 \%$ of baseline (Fig. S3; n $=8 ; P<0.01$, paired $t$-test). This is consistent with previous work demonstrating that trains of action potentials can potentiate EPSPs in other hippocampal interneurons (7). Secondly, this form of LTP was not prevented by blockade of NMDA receptors; thus, an increase in EPSP slope to $135 \pm 11 \%$ of baseline was seen in the presence of APV $(\mathrm{n}=6 ; P<0.05$, paired $t$-test $)$, similar in magnitude to LTP observed in interleaved controls (Fig. 2C; $136 \pm 8 \%, \mathrm{n}=15$ ). Inclusion of the $\mathrm{Ca}^{2+}$ chelator BAPTA $(10 \mathrm{mM})$ in the recording pipette, however, prevented induction of STDP, confirming the requirement for postsynaptic $\mathrm{Ca}^{2+}$ accumulation via a nonNMDA receptor-mediated mechanism (Fig. $2 D ; 70 \pm 8 \%, \mathrm{n}=4$ ). Interestingly, BAPTA converted potentiation into a late depression of EPSP slope $(P<0.05$, paired $t$-test $)$, consistent with a switch from LTP to LTD dependent on the size of the intracellular $\mathrm{Ca}^{2+}$ transient (4648). Finally, we assessed the involvement of postsynaptic VGCCs directly by applying $\mathrm{Ni}^{2+}$ $(100 \mu \mathrm{M})$ to block both T-type $\mathrm{Ca}^{2+}$ channels (which have been implicated in some forms of hippocampal interneuron LTP (49)) and R-type channels, and nimodipine (10 $\mu \mathrm{M})$ to block Ltype channels, which are activated by back-propagating APs in NGF cells (45) and have also been implicated in interneuron plasticity $(50,51)$. Application of these blockers together prevented the induction of LTP (Fig. $2 D ; 109 \pm 13 \% ; \mathrm{n}=5$ ). Taken together, these results suggest that $\mathrm{Ca}^{2+}$ influx through $\mathrm{T}-, \mathrm{R}$ - and/or L-type $\mathrm{Ca}^{2+}$ channels, likely triggered by backpropagating APs, is necessary for the induction of STDP in SLM interneurons, and sufficient on its own to induce a transient potentiation of synaptic transmission.

\section{LTP induction by stimulation of EC but not thalamic inputs to SLM interneurons.}

The SLM region of CA1 receives excitatory projections from both layer III of the EC (17) and the NRe of the thalamus (37). In order to activate either pathway selectively, we injected an adeno-associated virus (AAV) encoding channelrhodopsin-2 (ChR2) under the CaMKII promoter into either the NRe or the EC (Fig. 3A-C), and recorded responses in SLM interneurons to optogenetic stimulation of the surrounding ChR2-expressing terminals (Fig. $3 B$ and $C$ ). Importantly, viral injections in either location led to expression of ChR2 within the hippocampus that was restricted to SLM (Fig. $3 B$ and $C$ ), and, in the case of EC injections, the molecular layer of the dentate gyrus (Fig. 3C), as shown previously (40). Light stimulation reliably evoked EPSPs in SLM interneurons following expression of ChR2 in either set of fibers (Fig. $3 B$ and $C$ ). However, optogenetic responses were not stable over time and instead gradually increased in the absence of experimental manipulation (after 30 mins recording, 

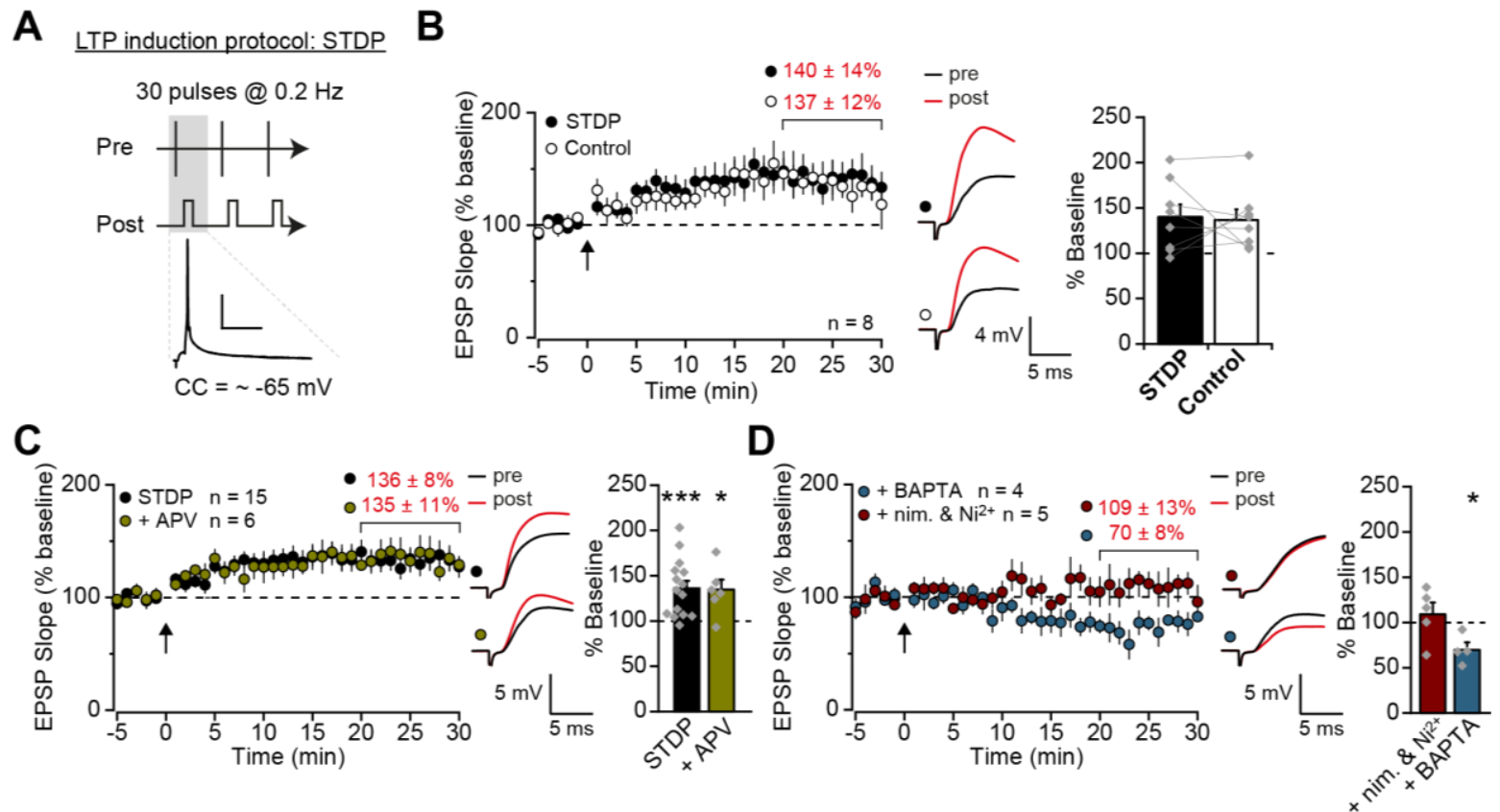

Fig. 2. Spike timing-dependent plasticity in SLM interneurons. (A) Schematic of the spike timingdependent plasticity (STDP) protocol, pairing 30 presynaptic stimulations with postsynaptic spikes. An example trace of a single pairing recorded from the postsynaptic cell is shown (scale: $25 \mathrm{mV}, 40 \mathrm{~ms}$ ). $\mathrm{CC}=$ current clamp. $(B)$ Pooled dataset showing that the STDP protocol induced LTP that was not pathway-specific, quantified on right. (C) Application of APV $(100 \mu \mathrm{M})$ did not block LTP induction by the STDP protocol, quantified on right. $(D)$ The STDP protocol failed to induce LTP in the presence of $\mathrm{Ni}^{2+}(100 \mu \mathrm{M})$ and nimodipine $(10 \mu \mathrm{M}$; nim.), and led to a reduction in response size when BAPTA $(10 \mathrm{mM})$ was added to the intracellular solution, quantified on right. * $P<0.05$, *** $P<0.001$. Error bars show SEM.

thalamus: $172 \pm 10 \%, \mathrm{n}=3$, Fig. S4A; EC: $127 \pm 16 \%$, $\mathrm{n}=4$, Fig. S4B), precluding the ability to measure LTP of these optogenetically evoked responses. For this reason, light stimulation was used to deliver a conditioning stimulus selectively to either EC or thalamic terminals, whilst electrical stimulation was used to monitor EPSPs at synapses made by both sets of afferents. Pairing optogenetic stimulation of EC inputs with depolarization, in a LFS-P protocol identical to that used in Figure 1 but with electrical stimulation interrupted (Fig. 3D), led to an increase in EPSP slope to $138 \pm 14 \%$ of baseline (Fig. $3 E ; \mathrm{n}=12 ; P<0.01$, paired $t$-test). In contrast, the same pairing applied to thalamic afferents had no observable effect, with the EPSP slope remaining at $107 \pm 9 \%$ of baseline (Fig. $3 F ; \mathrm{n}=11$ ). Notably, light-evoked responses were of similar amplitude whether stimulating EC or thalamic terminals, both during baseline recordings of EPSPs in current clamp (Fig. S5A; EC: $5.7 \pm 0.6 \mathrm{mV}, \mathrm{n}=12$; thalamus: $6.6 \pm 0.8$ $\mathrm{mV}, \mathrm{n}=11 ; P>0.05$, unpaired $t$-test), and during the LTP induction protocol in voltage clamp (Fig. S5B; EC: $-59.0 \pm 9.3$ pA, $\mathrm{n}=12$; thalamus: $-50.2 \pm 6.4 \mathrm{pA}, \mathrm{n}=11 ; P>0.05$, Mann- 
Whitney U test), suggesting that the different outcomes could not be explained by the degree of NGF cell depolarization. Interestingly, however, optogenetically evoked responses to stimulation of EC fibers, but not thalamic fibers, exhibited paired-pulse facilitation (PPF) (Fig. S5C; EC: $156 \pm 16 \%, \mathrm{n}=14$; thalamus: $100 \pm 7 \%, \mathrm{n}=13 ; P<0.01$, unpaired $t$-test), indicating likely differences in probability of release between these two synapses.
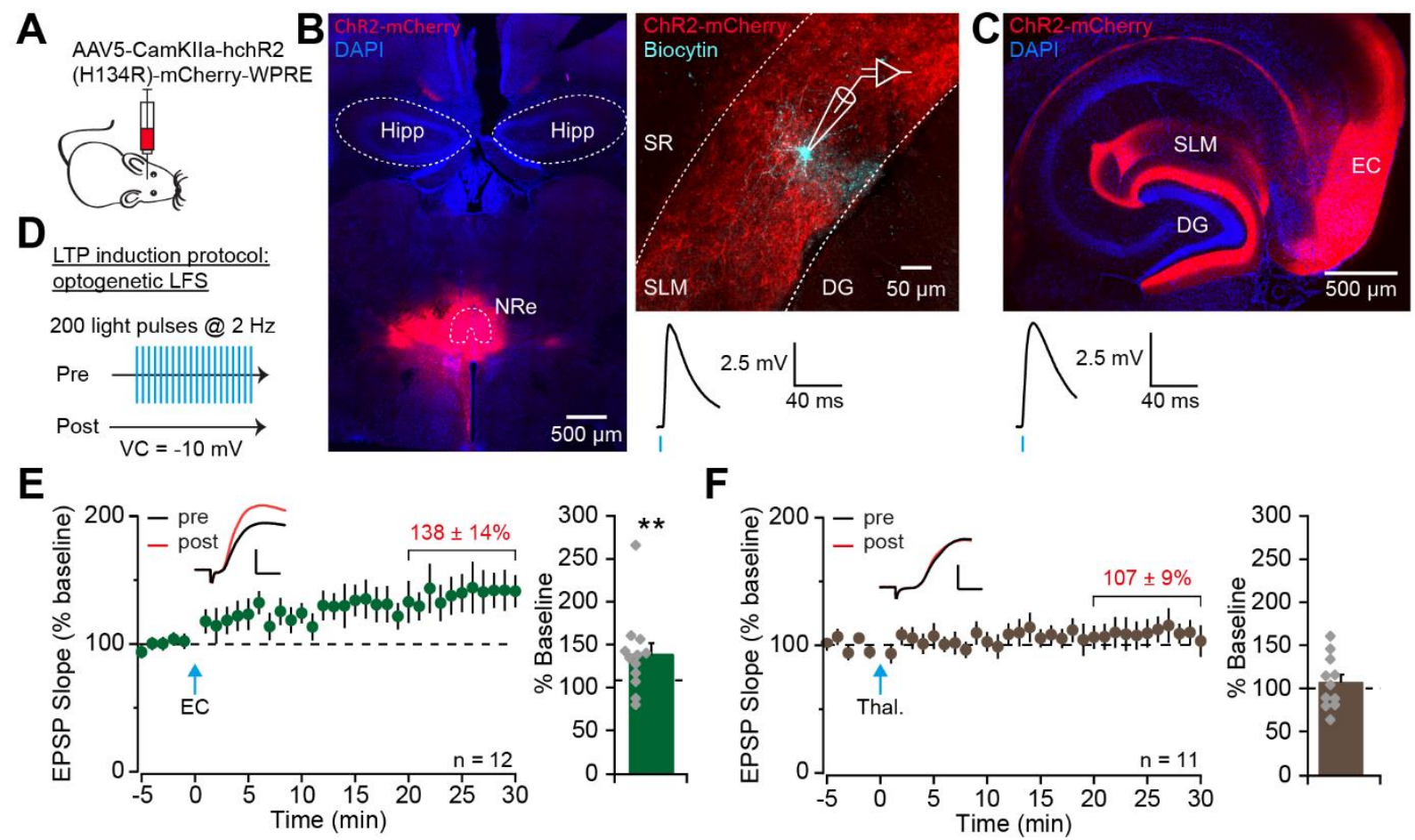

Fig. 3. LTP induction by stimulation of entorhinal cortex but not thalamic inputs to SLM interneurons. (A) Schematic showing viral strategy used to target the nucleus reuniens (NRe) of the thalamus or the entorhinal cortex (EC). (B) Confocal images of a coronal brain section $(70 \mu \mathrm{m})$ showing viral expression (red) at the injection site in the thalamus including the NRe, and DAPI staining (blue; left), and a sagittal hippocampal slice $(300 \mu \mathrm{m})$ showing a biocytin-filled SLM interneuron (cyan) surrounded by transduced thalamic fibers (red; right). Below: example light-induced EPSP recorded from the same cell (average 15 traces). Hipp. = hippocampus, $\mathrm{SR}=$ stratum radiatum, $\mathrm{DG}=$ dentate gyrus. (C) Confocal image of a horizontal brain section $(70 \mu \mathrm{m})$ showing viral expression (red) at the injection site in the EC, as well as in perforant path fibers in the SLM region of hippocampal CA1 and molecular layer of the dentate gyrus (DG), and DAPI staining (blue). Below: example light-induced EPSP recorded from an SLM interneuron in a mouse injected in the EC (average 15 traces). (D) Schematic of the optogenetic low-frequency stimulation-pairing (LFS-P) LTP induction protocol. $(E)$ Optogenetic LFS-P of EC fibers induced LTP, quantified on right. $(F)$ The same optogenetic stimulation 
protocol applied to thalamic fibers did not induce LTP, quantified on right. $* *=P<0.01$. Error bars show SEM.

\section{Hippocampal NDNF+ cells are NGF cells and express LTP.}

NGF cells constitute $\sim 10 \%$ of the total inhibitory neuron population in hippocampal area CA1, and the vast majority are located in SLM (35). This, together with our specific targeting of cells with NGF cell-like morphology, makes it highly likely that the plasticity identified and characterized here is a feature of this particular cell-type. Indeed, biocytin filling and post-hoc morphological reconstruction confirmed that at least some of the cells in which LTP was observed were in fact NGF interneurons (Fig. 4A). However, the fine dendritic and axonal arborisation of these cells renders morphological recovery particularly challenging (52), making it difficult to routinely confirm the identity of recorded cells. In order to directly address whether hippocampal NGF cells express LTP, we used Neuron-Derived Neurotrophic Factor (Ndnf)-Cre mice, a mouse line recently shown to specifically target NGF cells in cortical layer I ((41), see also (53)). As NDNF has thus far only been identified as an NGF cell-specific marker in the neocortex, we first sought to characterise hippocampal expression of NDNF+ cells by injecting the dorsal hippocampus of Ndnf-Cre mice with an AAV encoding Credependent ChR2 tagged with mCherry (Fig. 4B). NDNF+ cells were abundant in the hippocampus, and were found almost exclusively in SLM, consistent with the known location of NGF cells. Furthermore, near-rheobase current injections in NDNF+ cells revealed two populations with either early- or late-spiking properties (Fig. $4 B i, \mathrm{n}=20$ ), matching the firing pattern described in both cortical NDNF+ (41) and NGF (54) cells; other electrophysiological properties were also within the ranges described for both hippocampal (55) and cortical NGF $(54,56)$ cells, as well as NDNF+ cells ((41) Table S1). Finally, optogenetic activation of hippocampal NDNF+ cells produced long-lasting inhibitory responses in pyramidal neurons comprising a $\mathrm{GABA}_{\mathrm{A} \text {-slow }}$ and a strong $\mathrm{GABA}_{\mathrm{B}}$ component, evident both in the biphasic nature of the response and in the pharmacological dissection of its components (Fig. 4Bii and Table S2), both of which are notable hallmarks of NGF cell signaling $(34,57,58)$. Having confirmed the identity of hippocampal NDNF+ cells, we next tagged NGF cells by injecting Credependent EYFP into the dorsal hippocampus of Ndnf-Cre mice, and patched fluorescent cells in SLM. Application of the LFS-P protocol induced a clear increase in EPSP size to $144 \pm 20 \%$ of baseline (Fig. $4 C$ and $D ; \mathrm{n}=8 ; P<0.05$, Wilcoxon signed rank test), demonstrating that NGF cells exhibit robust LTP. 


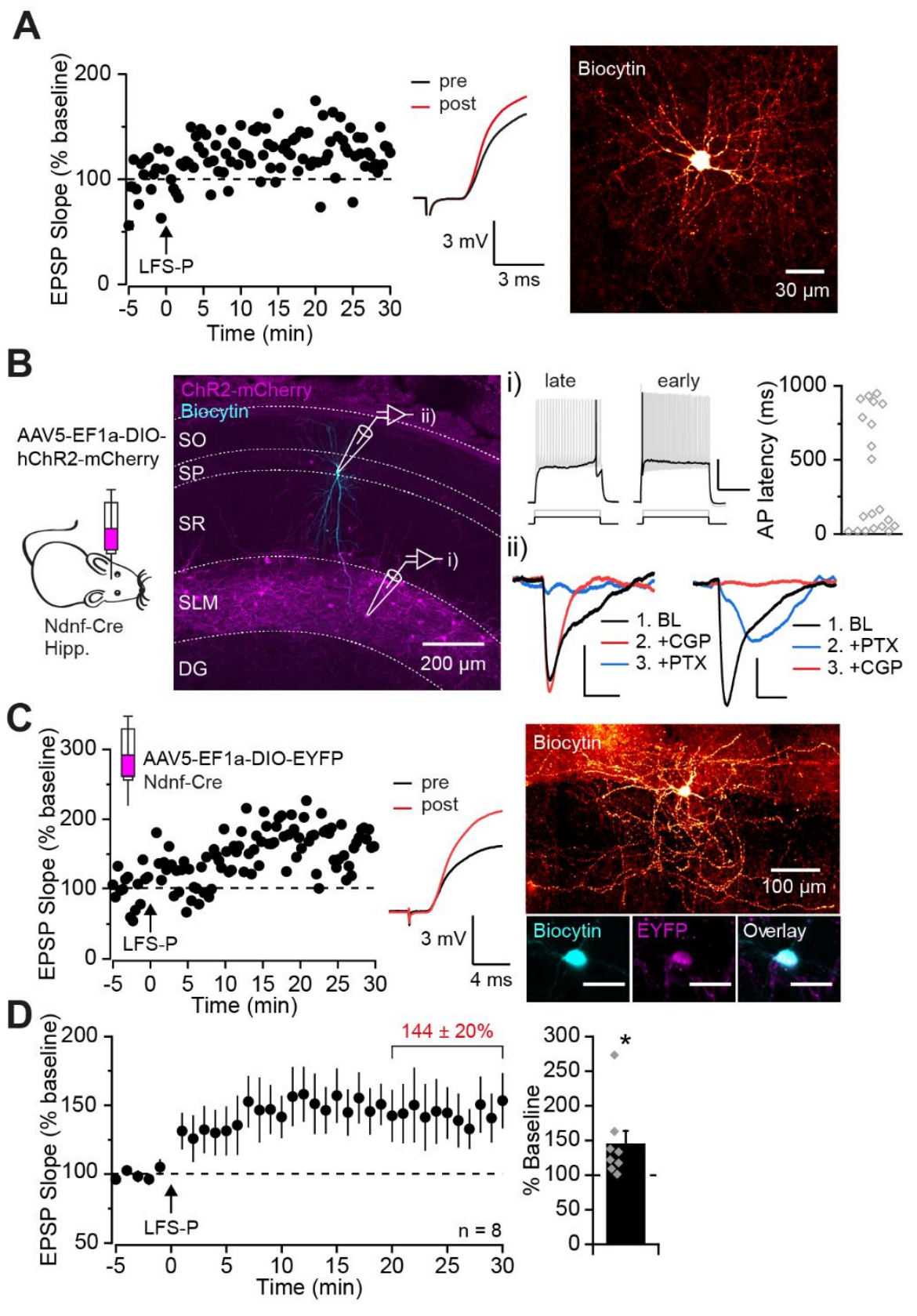

Fig. 4. Hippocampal NDNF+ cells are NGF cells and express LTP. $(A)$ Representative experiment and traces showing low-frequency stimulation-pairing (LFS-P) LTP (left) in a biocytin-filled cell with NGF cell-like morphology (right). (B) Schematic showing viral strategy used to express ChR2-mCherry in hippocampal NDNF+ cells (left), and confocal image of a sagittal hippocampal slice $(300 \mu \mathrm{m})$ showing selective expression in SLM neurons (magenta), and a biocytin-filled pyramidal cell (cyan) in stratum pyramidale $(\mathrm{SP})$. Hipp. = hippocampus, $\mathrm{SO}=$ stratum oriens, $\mathrm{SR}=$ stratum radiatum, $\mathrm{DG}=$ dentate gyrus. (i) mCherry-tagged NDNF+ cells showed late- or early-spiking properties in response to a near-rheobase current step (black; quantified on right, $\mathrm{n}=20$ ), and sustained spiking in response to a double-rheobase current step (gray; scale: $25 \mathrm{mV}, 500 \mathrm{~ms}$ ). (ii) Optogenetic stimulation of NDNF+ cells induced long-lasting IPSPs in pyramidal cells (black) that were abolished by blockers of $\mathrm{GABA}_{\mathrm{A}}$ (blue; PTX: picrotoxin, $100 \mu \mathrm{M}$ ) and $\mathrm{GABA}_{\mathrm{B}}$ (red; CGP: CGP 55845, $1 \mu \mathrm{M}$ ) receptors (scales: $1 \mathrm{mV}$, 
bioRxiv preprint doi: https://doi.org/10.1101/531822; this version posted January 27, 2019. The copyright holder for this preprint (which was not certified by peer review) is the author/funder, who has granted bioRxiv a license to display the preprint in perpetuity. It is made available under aCC-BY-NC-ND 4.0 International license.

$125 \mathrm{~ms}$ ). (C) Representative experiment and traces of LFS-P-induced LTP (left) in a biocytin-filled EYFP-tagged NDNF+ cell (right; bottom right scale bars: $30 \mu \mathrm{m})$. $(D)$ Pooled dataset showing LTP in NDNF+ NGF cells, quantified on right. $* P<0.05$. Error bars show SEM. 


\section{Discussion}

Here we show that interneurons located in SLM express NMDA receptor-dependent LTP and that $\mathrm{Ca}^{2+}$ influx via VGCCs can substitute for NMDA receptors during STDP. Furthermore, optogenetic stimulation of inputs originating in EC layer III induces LTP in these cells, while stimulation of those coming from the NRe of the thalamus, under the conditions tested here, does not. Importantly, we confirm that a recently developed Ndnf-Cre mouse line (41) selectively labels hippocampal NGF cells, and show, using this novel tool, that this prominent interneuron subtype expresses LTP.

Ndnf-Cre mice have, until now, only been used to label NGF cells located in cortical layer I $(41,53)$. Our results however indicate that this mouse line may also enable selective targeting of NGF cells within the hippocampus, in line with previously reported expression of NDNF in this subcortical structure (59). Thus, we show that hippocampal NDNF+ cells are located primarily within SLM, exhibit electrophysiological properties that are consistent with those previously described for both hippocampal $(55)$ and cortical $(41,54,56)$ NGF cells, and induce slow, long-lasting $\mathrm{GABA}_{\mathrm{A}}$ and $\mathrm{GABA}_{\mathrm{B}}$ receptor-mediated postsynaptic responses typical of NGF interneuron signaling $(34,57,58)$. This finding is significant, as it has so far not been possible to precisely target or manipulate hippocampal NGF cells. Indeed, whilst neuronal nitric oxide synthase (nNOS; $(45,60,61)$ ) and neuropeptide Y (NPY; $(55,62-65)$ ), amongst others, have been employed as markers to aid in their identification, neither of these are fully selective for NGF cells $(66,67)$. The Ndnf-Cre mouse line is thus the first genetic tool to achieve such selectivity, and will no doubt prove invaluable for investigations of hippocampal NGF cell function. Furthermore, a recent study showing that NDNF is a conserved marker for NGF cells in the human cortex (68) implies that results obtained with this mouse line can be translated to humans.

The finding that CA1 interneurons located in SLM, including an NGF cell subset, exhibit long-term plasticity has not, to our knowledge, previously been shown. Indeed, one previous study reported no evidence of LTP, although it focused on interneurons located at the border of SLM and stratum radiatum with stimulation of excitatory fibers in both strata (6). The present findings, however, complement work showing plasticity at mossy fiber inputs to SLM interneurons located in CA3 (50), as well as evidence of LTP in CA1 stratum radiatum Ivy cells (13), a cell-type closely related to NGF cells $(55,69)$, and of plasticity reported in cortical NDNF+ NGF cells (53). Interestingly, we found that LTP in SLM interneurons could 
be induced by both NMDA receptor-dependent and -independent mechanisms, and that plasticity induced by the former was at least partially pathway-specific. This supports previous reports of pathway-specific, NMDA receptor-dependent Hebbian LTP in aspiny hippocampal interneurons $(12,70)$, and further challenges the view that spines are necessary for the dendritic compartmentalization of plasticity $(71,72)$. In contrast, however, the NMDA receptorindependent form of LTP induced here by a STDP protocol was not restricted to the stimulated pathway. We hypothesize that back-propagating APs, which have been reported in SLM interneurons and NGF cells (45), triggered specifically by the STDP protocol, led to $\mathrm{Ca}^{2+}$ influx through VGCCs and thereby to LTP that was expressed indiscriminately throughout the dendritic tree. Indeed, induction of this form of plasticity was prevented by blocking T-/R- and L-type VGCCs, and postsynaptic APs alone without presynaptic stimulation were also sufficient to induce some potentiation, albeit not sustained. This is reminiscent of plasticity mechanisms seen in oriens-alveus interneurons, where NMDA receptor-independent LTP relies instead on $\mathrm{Ca}^{2+}$ influx through either $\mathrm{Ca}^{2+}$-permeable AMPA receptors or T-type $\mathrm{Ca}^{2+}$ channels, and can also be induced by trains of postsynaptic APs $(7,49)$. Together, these results indicate that postsynaptic $\mathrm{Ca}^{2+}$ is necessary for LTP induction in SLM interneurons, but that the source of $\mathrm{Ca}^{2+}$ itself can vary and may define the level of pathway-specificity.

It is interesting that optogenetic stimulation of EC fibers induces LTP in SLM interneurons whilst equivalent stimulation of thalamic fibers does not. This could be due to any number of pre- and/or post-synaptic differences that may exist between these two synapses, such as the specific receptors and receptor subunits present, the probability of release at each synapse, and the resultant short-term plasticity mechanisms that may be at play during the induction protocol. In support of the latter hypothesis, optogenetic dissection of the two inputs revealed that PPF could not be reliably induced at synapses formed by thalamic fibers, whilst clear PPF was seen at those originating from the EC. Although NRe stimulation has previously been shown to elicit PPF in hippocampal CA1 pyramidal cells, as measured by in vivo field recordings $(38,73-75)$, it is possible that the release probability at NRe fibers onto SLM interneurons is higher than that onto pyramidal cells, thereby reducing short-term facilitation selectively at this synapse. Indeed, the probability of release can vary in a target cell-dependent manner, even across synapses formed by the same presynaptic axon $(76,77)$. Thus, differences in LTP induction between EC and thalamic inputs could at least partly be explained by differences in probability of release that may exist between these two synapses. In addition, it is possible that differences in pre- and/or post-synaptic receptor expression could be involved 
in this effect. Given that LFS-P-induced LTP was found to be NMDA-receptor dependent, this receptor seems an obvious candidate. However, whilst a recent study strikingly showed that excitatory responses on NGF cells possess an unusually large NMDA component, they also demonstrated, using a similar optogenetic strategy to that employed here, that NMDA/AMPA ratios in NGF cells do not differ between NRe and EC inputs (40). It seems unlikely, then, that differences in expression of this receptor subtype could underlie our effect. Further characterization of these two distinct excitatory synapses onto SLM interneurons will be necessary to identify potential differences between them and better understand their individual functions and specific recruitment of hippocampal feed-forward inhibition.

The finding that multiple mechanisms, all converging on $\mathrm{Ca}^{2+}$ influx, can induce plasticity in SLM interneurons suggests that these inhibitory cells may be particularly susceptible to activity-dependent potentiation. Indeed, any stimulus capable of triggering repetitive APs could theoretically be sufficient to induce an enhancement of excitatory synaptic input to these cells. This raises the question of what function such plasticity in SLM interneurons, and NGF cells in particular, might serve. Feed-forward inhibition in the SLM is thought to impose a time window within which TA and Schaffer collateral inputs can interact nonlinearly $(33,66)$, and thus likely plays a permissive role on the generation of dendritic spikes $(78)$, plateau potentials and plasticity $(26,27)$ in CA1 pyramidal cells. Interestingly, inhibition in layer I of the cortex, mediated largely by NGF cells (54), has been proposed to play an analogous role in regulating dendritic nonlinearities generated by input coupling (79), and activation of cortical NDNF+ NGF cells has directly been shown to inhibit the generation of dendritic spikes in layer $\mathrm{V}$ pyramidal neurons (53). It seems likely, then, that plasticity of excitatory inputs onto NGF cells, both within the hippocampus and cortex (if indeed it occurs there), may result in tighter regulation of supralinear dendritic integration in pyramidal cells. It is important to note, however, that NGF cells are also strongly interconnected, both electrically and synaptically (34), and that their signaling is subject to powerful activity-dependent downregulation via activation of presynaptic $\operatorname{GABA}_{B}$ receptors $(34,80)$, desensitization of postsynaptic $\mathrm{GABA}_{\mathrm{A}}$ receptors (81), and nitric oxide-mediated auto-inhibition (45). It is therefore difficult to predict the net effect of NGF cell potentiation on downstream hippocampal signaling. Future experiments employing optogenetic strategies in Ndnf-Cre mice will be key to understanding the roles of this hitherto relatively understudied interneuron class, and of potentiation of TA feed-forward inhibition, within the wider hippocampal network. 


\section{Materials and Methods}

\section{Animals}

Hippocampal slices were prepared from male and female wild-type mice (C57BL/6, Harlan) that were postnatal day $14-25$ for electrically induced LTP experiments (Figs. 1 \& 2), or 2 5 months old for optogenetic experiments (Fig. 3). Heterozygous Ndnf-Cre breeding pairs were obtained from The Jackson Laboratory (Ndnf-IRES2-dgCre-D), and bred on a C57BL/6 background. Male and female 3 - 5 month old Ndnf-Cre mice were used for NGF cell LTP experiments (Fig. 4). All mice were housed under a non-reversed $12 \mathrm{~h}$ light-dark cycle and were given access to food and water ad libitum. All procedures were performed in accordance with the UK Home Office Animals (Scientific Procedures) Act 1986.

\section{Surgery for viral injections}

Mice (minimum age 6 weeks) were anaesthetized using isoflurane and positioned in a stereotaxic frame, and on a heated pad to maintain body temperature. Either bilateral holes were made in the skull for hippocampal and EC injections, or a single hole was made in the midline for injections into the NRe. The coordinates used for each location were: EC: $-4.3 \mathrm{~mm}$ caudal and $+/-3.0 \mathrm{~mm}$ lateral of Bregma, and -3.2 and -3.0 $\mathrm{mm}$ deep from the pia with the syringe angled at $12-14^{\circ}$; NRe: $-0.7 \mathrm{~mm}$ caudal, on the midline, and $-4.4,-4.2$ and $-4.0 \mathrm{~mm}$ deep; dorsal CA1 (SLM): -2.0 mm caudal and +/-1.25 mm lateral, -1.65 and -1.45 mm deep. The viral suspension $(200 \mathrm{nl})$ was injected at each site $(100 \mathrm{nl} / \mathrm{min})$ through a 33 gauge needle using a Hamilton syringe, and the needle was left for $5 \mathrm{~min}$ post-injection before being withdrawn. The viruses used were AAV5-CaMKII $\alpha$-hchR2(H134R)-mCherry-WPRE, AAV5EF1 $\alpha$-DIO-EYFP and AAV5-EF1a-DIO-hChR2-mCherry (all titres $>10^{12}$ ) and were purchased from UNC Vector Core. Experiments were performed a minimum of 3 weeks postsurgery to allow for viral expression to occur.

\section{Slice preparation}

Young mice (P14 - 25) were decapitated under isoflurane anaesthesia and the brains were rapidly removed and placed in ice-cold, sucrose-rich slicing solution composed of (in $\mathrm{mM}$ ): sucrose (75), $\mathrm{NaCl}$ (87), $\mathrm{KCl}$ (2.5), $\mathrm{NaH}_{2} \mathrm{PO}_{4}$ (1.25), $\mathrm{NaHCO}_{3}(25)$, Glucose (25), $\mathrm{CaCl}_{2}$ (0.5), $\mathrm{MgCl}_{2}$ (7), and oxygenated with $95 \% \mathrm{O}_{2}$ and $5 \% \mathrm{CO}_{2}$. Older mice ( $\geq 2$ months) were given a lethal dose of sodium pentobarbital, and transcardially perfused with ice-cold oxygenated sucrose solution, before removal of the brain. $300 \mu \mathrm{m}$-thick sagittal slices were cut, except for 
a subset of brains that were cut in a horizontal orientation; results from experiments in sagittal and horizontal slices did not differ and were pooled for analysis. Slices were cut in ice-cold sucrose solution using a vibrating microtome (Leica VT1200 S), and were left to recover for $15 \mathrm{~min}$ at $32^{\circ} \mathrm{C}$ before being transferred to a standard artificial cerebrospinal fluid (aCSF) solution composed of (in mM): $\mathrm{NaCl}$ (119), $\mathrm{KCl}$ (2.5), $\mathrm{MgSO} 4$ (1.3), $\mathrm{NaH}_{2} \mathrm{PO}_{4}$ (1.25), $\mathrm{NaHCO}_{3}(25)$, Glucose (11), $\mathrm{CaCl}_{2}$ (2.5), and oxygenated with $95 \% \mathrm{O}_{2}$ and $5 \% \mathrm{CO}_{2}$. Slices were allowed to recover for at least $1 \mathrm{~h}$ at room temperature before being transferred to a recording chamber for experiments. The CA3 region was removed from all slices to prevent recurrent activity in the presence of GABA receptor blockers.

\section{Electrophysiology}

Recording: Experiments were performed in a submerged recording chamber continuously perfused with oxygenated $\mathrm{aCSF}$ at a rate of $2-3 \mathrm{ml} / \mathrm{min}$ and maintained at $30-32^{\circ} \mathrm{C}$. Picrotoxin $(100 \mu \mathrm{M})$ and CGP55845 $(1 \mu \mathrm{M})$ were routinely added to block $\mathrm{GABA}_{\mathrm{A}}$ and $\mathrm{GABA}_{\mathrm{B}}$ receptors, respectively. Slices were visualized using an upright microscope (BX51WI, Olympus) and differential interference contrast (DIC) optics were used to identify cells located in the SLM layer of CA1. In wild-type mice, cells with small $(\sim 10 \mu \mathrm{m})$, round somata were selected for experiments, in line with known NGF cell morphology (34). In Ndnf-Cre mice, EYFP- or mCherry-tagged NDNF+ cells were identified using blue $(470 \mathrm{~nm})$ or orange (590 $\mathrm{nm}$ ) LED lights, respectively (ThorLabs) delivered through the microscope objective (20X; Olympus). Whole cell patch clamp recordings were performed using borosilicate glass micropipettes $\left(2-4 \mathrm{M} \Omega\right.$ ) containing a $\mathrm{K}^{+}$-based internal solution composed of (in $\mathrm{mM}$ ): $\mathrm{K}$ gluconate (145), NaCl (8), KOH-HEPES (10), EGTA (0.2), Mg-ATP (2), Na3-GTP (0.3). Biocytin (0.4\%) was added for post-hoc morphological analysis in a subset of experiments. Recordings were made using a Multiclamp 700B amplifier (Molecular Devices), filtered at 10 $\mathrm{kHz}$ and digitized at $20 \mathrm{kHz}$, and experiments were run using custom-made LabVIEW software. Recordings were not corrected for liquid junction potential, and cells were rejected if they had an access resistance $>25 \mathrm{M} \Omega$, or access or input resistance that changed by more than $20 \%$ over the course of an experiment. Recordings were made in current clamp mode at $70 \mathrm{mV}$, except during the LFS-P or HFS protocols during which cells were temporarily switched to voltage clamp and held at $-10 \mathrm{mV}$.

Stimulation: Concentric bipolar stimulating electrodes (FHC) were positioned in the SLM and stimulation was delivered at $0.05 \mathrm{~Hz}$ via constant current stimulators (Digitimer). In 
experiments where 2 pathways were tested, stimulating electrodes were positioned on either side of the recorded cell, at opposite ends of SLM, and pathway independence was verified by comparing responses to paired-pulse stimulation within and across pathways (see Fig. S2): paired-pulses with an inter-pulse interval of $50 \mathrm{~ms}$ were applied to each pathway and typically revealed paired-pulse facilitation (PPF) ((EPSP slope $1 /$ EPSP slope $\left.\left._{2}\right) * 100 ; 176 \pm 5 \% ; \mathrm{n}=58\right)$. Paired-pulses were then applied across pathways, and pathways were considered independent if responses were not facilitated following stimulation of the other pathway. It should be noted that spikes were often triggered by larger EPSPs, thus preventing the measurement of PPF and pathway overlap in some cells; however, all pathways that could be tested were found to be independent ( $\mathrm{n}=29$ pairs), suggesting that our stimulating electrode placement generally activated different sets of fibers. During experiments, stimulation was delivered to each pathway alternately at a frequency of $0.05 \mathrm{~Hz}$. Stimulation intensity for all electrically-induced LTP experiments was set to elicit sub-maximal responses measuring $\sim 5 \mathrm{mV}$ in amplitude. For optogenetic stimulation of thalamic or EC fibers, $1 \mathrm{~ms}$-long pulses of blue light $(470 \mathrm{~nm})$ were delivered through the microscope objective, and experiments were performed on those cells in which an EPSP of amplitude $\geq 2.5 \mathrm{mV}$ could be induced. LTP induction protocols were as follows: LFS-P: 200 pulses (electrical or optogenetic) delivered at $2 \mathrm{~Hz}$, while holding the cell at $-10 \mathrm{mV}$ in voltage clamp; HFS: 2 bursts of 100 pulses at $100 \mathrm{~Hz}$, delivered $20 \mathrm{sec}$ apart, while holding the cell at $-10 \mathrm{mV}$ in voltage clamp; STDP: 30 pulses delivered at $0.2 \mathrm{~Hz}$, paired with $5 \mathrm{~ms}$-long depolarizing current steps to induce 1 AP in the postsynaptic cell $\sim 10 \mathrm{~ms}$ after presynaptic stimulation (cells were maintained at $-65 \mathrm{mV}$ in current clamp throughout this protocol to ensure sufficient depolarization for AP firing). Electrophysiological properties of cells were assessed by injection of 1 s-long current steps, ranging from -200 pA to +300 pA in $50 \mathrm{pA}$ increments. Rheobase current was also identified (minimal current injection required to evoke 1 AP), and a 1 s-long current step at twice rheobase delivered in order to assess firing frequency and adaptation; the latter was measured as the ratio between the firing frequency observed during the last $200 \mathrm{~ms}$ and that seen during the first $200 \mathrm{~ms}$ of the current step. Input resistance was measured and averaged from the -50 and $+50 \mathrm{pA}$ steps, and membrane time constant $(\tau)$ was calculated by fitting a single exponential function to the first $150 \mathrm{~ms}$ of the 50 pA step. Sag was calculated in two ways from the -200 pA current step: 1) as an absolute measure $(\mathrm{mV})$ of the negative deflection seen at the start of the step, taken as the difference between the peak negative value and the steady state voltage measured at the end of the step (last $300 \mathrm{~ms}$ ), and 2) this absolute value expressed as a percentage of the total negative deflection evoked by the $-200 \mathrm{pA}$ current injection, to take into account differences in input 
resistance across cells. AP and afterhyperpolarization (AHP) properties were calculated from the single AP evoked at rheobase current.

Cell fixation and histochemistry: Cells were filled with biocytin during whole-cell recordings and slices were placed in $4 \%$ paraformaldehyde overnight at $4^{\circ} \mathrm{C}$. Fixed slices were rinsed 3 times in phosphate buffered saline (PBS), and subsequently stored in PBS containing $0.02 \%$ sodium azide. Biocytin was revealed by incubating slices in PBS with $0.3 \%$ Triton-X and streptavidin-conjugated Alexa Fluor (488 or 594, 1:1000; ThermoFisher Scientific, 21832 or S11227) for $3 \mathrm{~h}$ at room temperature. Some of the slices from Ndnf-Cre mice that had been injected with AAV5-EF1 $\alpha$-DIO-EYFP were also stained for GFP to enhance the EYFP-tag and confirm the identity of recorded cells. For these stainings, slices were first incubated in blocking solution consisting of $0.5 \%$ Triton-X, $0.5 \%$ bovine serum albumin (BSA) and $10 \%$ goat serum in PBS for $1 \mathrm{~h}$ at room temperature, before being transferred to PBS containing $0.5 \%$ Triton-X, 0.5\% BSA and guinea pig anti-GFP antibody (1:1000; Synaptic Systems, 132 005) and left overnight at $4^{\circ} \mathrm{C}$. After washing in PBS, slices were incubated in goat anti-guinea pig secondary antibody conjugated with Alexa Fluor 488 (1:500; ThermoFisher Scientific, A11073) and streptavidin-conjugated Alexa Fluor 594 (1:1000; ThermoFisher Scientific, S1127). DAPI staining was then performed by incubating slices for $5 \mathrm{~min}$ in PBS with DAPI $(1: 5000)$.

Data analysis: Individual experiments were analyzed using custom code written in Python, and statistical analysis was carried out in Origin (2018; OriginLab). For quantification of LTP, paired students $t$-tests were carried out on raw pre (baseline) vs post-LTP (last $10 \mathrm{~min}$ ) EPSP slope measurements. Test versus control pathways were compared using paired $t$-tests on normalized responses averaged from the last $10 \mathrm{~min}$ of experiments, and unpaired $t$-tests were used to compare optogenetic responses to thalamic versus EC stimulation. Shapiro-Wilk tests were used to assess normality, and paired and unpaired $t$-tests were replaced by Wilcoxon signed rank and Mann-Whitney $U$ tests, respectively, if data were found to be non-normally distributed. Differences were considered significant when $P<0.05$, and are reported as $P<$ 0.001 (**) $^{* *} P<0.01$ (**) $^{*} P<0.05$ (*) $^{*}$, or $P=\mathrm{X}$ when results were near-significant $(P<0.1)$. All data are presented as mean \pm SEM. Representative traces are an average of 15 traces taken during the $5 \mathrm{~min}$ baseline period or during the last $5 \mathrm{~min}$ of recordings, unless stated otherwise. 


\section{Author contributions}

All authors contributed to experimental design. Experiments were performed by M.S.M. and analyzed by M.S.M and J.C.. Characterization of the Ndnf-Cre mouse line was carried out by M.S.M and V.M.. M.S.M. and D.M.K wrote the manuscript, which was revised by all coauthors.

\section{Acknowledgements}

This work was supported by the Wellcome Trust and Epilepsy Research UK (D.M.K). 


\section{References}

1. Kullmann DM, Moreau AW, Bakiri Y, Nicholson E (2012) Plasticity of inhibition. Neuron 75(6):951-962.

2. Kullmann DM, Lamsa KP (2007) Long-term synaptic plasticity in hippocampal interneurons. Nat Rev Neurosci 8(9):687-699.

3. Pelletier JG, Lacaille JC (2008) Long-term synaptic plasticity in hippocampal feedback inhibitory networks (Elsevier) doi:10.1016/S0079-6123(07)00014-3.

4. Bartos M, Alle H, Vida I (2011) Role of microcircuit structure and input integration in hippocampal interneuron recruitment and plasticity. Neuropharmacology 60(5):730739.

5. Lamsa KP, Heeroma JH, Somogyi P, Rusakov D a, Kullmann DM (2007) Anti-Hebbian long-term potentiation in the hippocampal feedback inhibitory circuit. Science 315(5816):1262-1266.

6. Ouardouz M, Lacaille JC (1995) Mechanisms of selective long-term potentiation of excitatory synapses in stratum oriens / alveus interneurons of rat hippocampal slices. $J$ Neurophysiol 73(2):810-819.

7. Nicholson E, Kullmann DM (2014) Long-term potentiation in hippocampal oriens interneurons: postsynaptic induction, presynaptic expression and evaluation of candidate retrograde factors. Philos Trans R Soc B Biol Sci 369:20130133.

8. Griguoli M, Cellot G, Cherubini E (2013) In hippocampal oriens interneurons antiHebbian long-term potentiation requires cholinergic signaling via $\alpha 7$ nicotinic acetylcholine receptors. J Neurosci 33(3):1044-1049.

9. Cowan AI, Stricker C, Reece LJ, Redman SJ (1998) Long-term plasticity at excitatory synapses on aspinous interneurons in area CA1 lacks synaptic specificity. $J$ Neurophysiol 79(1):13-20.

10. Wang JH, Kelly P (2001) Calcium-calmodulin signalling pathway up-regulates glutamatergic synaptic function in non-pyramidal, fast spiking rat hippocampal CA1 neurons. J Physiol 533(2):407-422.

11. Le Roux N, Cabezas C, Böhm UL, Poncer JC (2013) Input-specific learning rules at 
excitatory synapses onto hippocampal parvalbumin-expressing interneurons. J Physiol 591(7):1809-1822.

12. Lamsa K, Heeroma JH, Kullmann DM (2005) Hebbian LTP in feed-forward inhibitory interneurons and the temporal fidelity of input discrimination. Nat Neurosci 8(7):916924.

13. Szabo A, et al. (2012) Calcium-permeable AMPA receptors provide a common mechanism for LTP in glutamatergic synapses of distinct hippocampal interneuron types. J Neurosci 32(19):6511-6516.

14. Levy WB, Colbert CM, Desmond NL (1995) Another network model bites the dust: Entorhinal inputs are no more than weakly excitatory in the hippocampal CA1 region. Hippocampus 5(2):137-140.

15. Dvorak-Carbone H, Schuman EM (1999) Patterned activity in stratum lacunosum moleculare inhibits CA1 pyramidal neuron firing. J Neurophysiol 82(6):3213-3222.

16. Williams S, Lacaille JC (1992) GABAB receptor-mediated inhibitory postsynaptic potentials evoked by electrical stimulation and by glutamate stimulation of interneurons in stratum lacunosum-moleculare in hippocampal CA1 pyramidal cells in vitro. Synapse 11(3):249-258.

17. Witter MP, Griffioen AW, Jorritsma-Byham B, Krijnen JLM (1988) Entorhinal projections to the hippocampal CA1 region in the rat: an underestimated pathway. Neurosci Lett 85(2):193-198.

18. Yeckel MF, Berger TW (1990) Feedforward excitation of the hippocampus by afferents from the entorhinal cortex: Redefinition of the role of the trisynaptic pathway. Proc Natl Acad Sci U S A 87:5832-5836.

19. Colbert CM, Levy WB (1992) Electrophysiological and pharmacological characterization of perforant path synapses in CA1: mediation by glutamate receptors. $J$ Neurophysiol 68(1):1-8.

20. Empson RM, Heinemann U (1995) Perforant path connections to area CA1 are predominantly inhibitory in the rat hippocampal-entorhinal cortex combined slice preparation. Hippocampus 5(2):104-107.

21. Dudman JT, Tsay D, Siegelbaum SA (2007) A role for synaptic inputs at distal 
dendrites: instructive signals for hippocampal long-term plasticity. Neuron 56(5):866879.

22. Takahashi H, Magee JC (2009) Pathway interactions and synaptic plasticity in the dendritic tuft regions of CA1 pyramidal neurons. Neuron 62(1):102-111.

23. Judge SJ, Hasselmo ME (2004) Theta rhythmic stimulation of stratum lacunosummoleculare in rat hippocampus contributes to associative LTP at a phase offset in stratum radiatum. J Neurophysiol 92(3):1615-1624.

24. Han EB, Heinemann SF (2013) Distal dendritic inputs control neuronal activity by heterosynaptic potentiation of proximal inputs. J Neurosci 33(4):1314-1325.

25. Basu J, et al. (2013) A cortico-hippocampal learning rule shapes inhibitory microcircuit activity to enhance hippocampal information flow. Neuron 79(6):1208-1221.

26. Bittner $\mathrm{KC}$, et al. (2015) Conjunctive input processing drives feature selectivity in hippocampal CA1 neurons. Nat Neurosci 18(8):1133-1142.

27. Remondes M, Schuman EM (2002) Direct cortical input modulates plasticity and spiking in CA1 pyramidal neurons. Nature 416(6882):736-740.

28. Levy WB, Desmond NL, Zhang DX (1998) Perforant path activation modulates the induction of long-term potentiation of the schaffer collateral-hippocampal CA1 response: Theoretical and experimental analyses. Learn Mem 4(6):510-518.

29. Wozny C, et al. (2005) Entorhinal cortex entrains epileptiform activity in CA1 in pilocarpine-treated rats. Neurobiol Dis 19(3):451-460.

30. Booth CA, et al. (2016) Altered intrinsic pyramidal neuron properties and pathwayspecific synaptic dysfunction underlie aberrant hippocampal network function in a mouse model of tauopathy. J Neurosci 36(2):350-363.

31. Klausberger T (2009) GABAergic interneurons targeting dendrites of pyramidal cells in the CA1 area of the hippocampus. Eur J Neurosci 30(6):947-957.

32. Vida I, Halasy K, Szinyei C, Somogyi P, Buhl EH (1998) Unitary IPSPs evoked by interneurons at the stratum radiatum - stratum lacunosum-moleculare border in the CA1. J Physiol 506(3):755-773.

33. Capogna M (2011) Neurogliaform cells and other interneurons of stratum lacunosum- 
moleculare gate entorhinal-hippocampal dialogue. J Physiol 589(Pt 8):1875-1883.

34. Price CJ, et al. (2005) Neurogliaform neurons form a novel inhibitory network in the hippocampal CA1 area. J Neurosci 25(29):6775-6786.

35. Bezaire MJ, Soltesz I (2013) Quantitative assessment of CA1 local circuits: Knowledge base for interneuron-pyramidal cell connectivity. Hippocampus 23(9):751-785.

36. Oláh S, et al. (2009) Regulation of cortical microcircuits by unitary GABA-mediated volume transmission. Nature 461(7268):1278-1281.

37. Wouterlood FG, Saldana E, Witter MP (1990) Projection from the nucleus reuniens thalami to the hippocampal region: Light and electron microscopic tracing study in the rat with the anterograde tracer Phaseolus vulgaris-leucoagglutinin. J Comp Neurol 296(2):179-203.

38. Dolleman-Van der Weel MJ, Lopes da Silva FH, Witter MP (1997) Nucleus reuniens thalami modulates activity in hippocampal field CA1 through excitatory and inhibitory mechanisms. J Neurosci 17(14):5640-5650.

39. Dolleman-Van Der Weel MJ, Witter MP (2000) Nucleus reuniens thalami innervates $\gamma$ aminobutyric acid positive cells in hippocampal field CA1 of the rat. Neurosci Lett 278(3):145-148.

40. Chittajallu R, et al. (2017) Afferent specific role of NMDA receptors for the circuit integration of hippocampal neurogliaform cells. Nat Commun 8(152):1-13.

41. Tasic B, et al. (2016) Adult mouse cortical cell taxonomy revealed by single cell transcriptomics. Nat Neurosci 19(2):335-346.

42. Maccaferri G, McBain CJ (1996) Long-term potentiation in distinct subtypes of hippocampal nonpyramidal neurons. J Neurosci 16(17):5334-5343.

43. Cowan AI, Stricker C, Reece LJ, Redman SJ (1998) Long-term plasticity at excitatory synapses on aspinous interneurons in area CA1 lacks synaptic specificity. $J$ Neurophysiol 79(1):13-20.

44. Chen Y, Sabatini BL (2012) Signaling in dendritic spines and spine microdomains. Curr Opin Neurobiol 22(3):389-396.

45. Li G, Stewart R, Canepari M, Capogna M (2014) Firing of hippocampal neurogliaform 
cells induces suppression of synaptic inhibition. J Neurosci 34(4):1280-1292.

46. Artola A, Singer W (1993) Long-term depression of excitatory synaptic transmission and its relationship to long-term potentiation. Trends Neurosci 16(11):480-487.

47. Kimura F, Tsumoto T, Nishigori A, Yoshimura Y (1990) Long-term depression but not potentiation is induced in $\mathrm{Ca}(2+)$-chelated visual cortex neurons. Neuroreport 1(1):6568.

48. Shouval H (2010) Spike timing dependent plasticity: a consequence of more fundamental learning rules. Front Comput Neurosci 4(July):1-13.

49. Nicholson E, Kullmann DM (2017) T-type calcium channels contribute to NMDA receptor independent synaptic plasticity in hippocampal regular-spiking oriens-alveus interneurons. J Physiol 595(11):3449-3458.

50. Galván EJ, Calixto E, Barrionuevo G (2008) Bidirectional Hebbian plasticity at hippocampal mossy fiber synapses on CA3 interneurons. J Neurosci 28(52):1404214055.

51. Topolnik L, Chamberland S, Pelletier J-G, Ran I, Lacaille J-C (2009) Activitydependent compartmentalized regulation of dendritic $\mathrm{Ca} 2+$ signaling in hippocampal interneurons. J Neurosci 29(14):4658-4663.

52. Tremblay R, Lee S, Rudy B (2016) GABAergic interneurons in the neocortex: from cellular properties to circuits. Neuron 91(2):260-292.

53. Abs E, et al. (2018) Learning-related plasticity in dendrite-targeting layer 1 interneurons. Neuron 100(3):684-699.

54. Jiang X, et al. (2015) Principles of connectivity among morphologically defined cell types in adult neocortex. Science (80- ) 350(6264):aac9462-aac9462.

55. Tricoire L, et al. (2010) Common origins of hippocampal Ivy and nitric oxide synthase expressing neurogliaform cells. J Neurosci 30(6):2165-2176.

56. Karagiannis A, et al. (2009) Classification of NPY-expressing neocortical interneurons. J Neurosci 29(11):3642-3659.

57. Capogna M, Pearce RA (2011) GABAA,slow: causes and consequences. Trends Neurosci 34(2):101-112. 
58. Tamas G (2003) Identified sources and targets of slow inhibition in the neocortex. Science (80- ) 299(5614):1902-1905.

59. Kuang X-L, et al. (2010) Spatio-temporal expression of a novel neuron-derived neurotrophic factor (NDNF) in mouse brains during development. BMC Neurosci 11(137):1-11.

60. Bloss EB, et al. (2016) Structured dendritic inhibition supports branch-selective integration in CA1 pyramidal cells. Neuron 89(5):1016-1030.

61. Taniguchi H, et al. (2011) A resource of Cre driver lines for genetic targeting of GABAergic neurons in cerebral cortex. Neuron 71:995-1013.

62. Li Q, Bartley AF, Dobrunz LE (2017) Endogenously released neuropeptide Y suppresses hippocampal short-term facilitation and is impaired by stress-induced anxiety. J Neurosci 37(1):23-37.

63. Krook-Magnuson E, Luu L, Lee S-H, Varga C, Soltesz I (2011) Ivy and neurogliaform interneurons are a major target of -opioid receptor modulation. J Neurosci 31(42):14861-14870.

64. Chittajallu R, Pelkey K a, McBain CJ (2013) Neurogliaform cells dynamically regulate somatosensory integration via synapse-specific modulation. Nat Neurosci 16(1):13-15.

65. Jackson J, Karnani MM, Zemelman B V., Burdakov D, Lee AK (2018) Inhibitory control of prefrontal cortex by the claustrum. Neuron 99:1-11.

66. Overstreet-Wadiche L, McBain CJ (2015) Neurogliaform cells in cortical circuits. Nat Rev Neurosci 16(8):458-468.

67. Pelkey KA, et al. (2017) Hippocampal GABAergic inhibitory interneurons. Physiol Rev 97(4):1619-1747.

68. Poorthuis RB, et al. (2018) Rapid neuromodulation of layer 1 interneurons in human neocortex. Cell Rep 23(4):951-958.

69. Armstrong C, Krook-Magnuson E, Soltesz I (2012) Neurogliaform and Ivy cells: a major family of nNOS expressing GABAergic neurons. Front Neural Circuits 6(May):1-10.

70. Galván EJ, et al. (2015) Synapse-specific compartmentalization of signaling cascades 
for LTP induction in CA3 interneurons. Neuroscience 290:332-345.

71. Yuste R, Majewska A, Holthoff K (2000) From form to function: calcium compartmentalization in dendritic spines. Nat Neurosci 3(7):653-659.

72. Nimchinsky EA, Sabatini BL, Svoboda K (2002) Structure and function of dendritic spines. Annu Rev Physiol 64:313-353.

73. Gruart A, Sánchez-Campusano R, Fernández-Guizán A, Delgado-García JM (2015) A differential and timed contribution of identified hippocampal synapses to associative learning in mice. Cereb Cortex 25(9):2542-2555.

74. Bertram EH, Zhang DX (1999) Thalamic excitation of hippocampal CA1 neurons: a comparison with the effects of CA3 stimulation. Neuroscience 92(1):15-26.

75. Dolleman-van der Weel MJ, Lopes da Silva FH, Witter MP (2017) Interaction of nucleus reuniens and entorhinal cortex projections in hippocampal field CA1 of the rat. Brain Struct Funct 222(5):2421-2438.

76. Koester HJ, Johnston D (2005) Target cell-dependent normalization of transmitter release at neocortical synapses. Science (80- ) 308(5723):863-866.

77. Branco T, Staras K (2009) The probability of neurotransmitter release: variability and feedback control at single synapses. Nat Rev Neurosci 10:373-383.

78. Jarsky T, Roxin A, Kath WL, Spruston N (2005) Conditional dendritic spike propagation following distal synaptic activation of hippocampal CA1 pyramidal neurons. Nat Neurosci 8(12):1667-1676.

79. Larkum ME, Zhu JJ, Sakmann B (1999) A new cellular mechanism for coupling inputs arriving at different cortical layers. Nature 398(6725):338-341.

80. Price CJ, Scott R, Rusakov DA, Capogna M (2008) GABA(B) receptor modulation of feedforward inhibition through hippocampal neurogliaform cells. J Neurosci 28(27):6974-6982.

81. Karayannis T, et al. (2010) Slow GABA transient and receptor desensitization shape synaptic responses evoked by hippocampal neurogliaform cells. J Neurosci 30(29):9898-9909. 